\title{
ANALYSIS OF HIGH PERFORMANCE CONCRETE WITH STEEL FIBER REINFORCEMENT
}

\author{
Thi My Dung DO ${ }^{1}$, ThanhQuangKhai LAM ${ }^{2 *}$, Van Thuc NGO $^{3} \&$ Thi Thu Nga NGUYEN ${ }^{4}$ \\ ${ }^{1,2,3}$ MienTay Construction University, 20B Pho Co Dieu street, ward 3, Vinh Long, Vietnam \\ ${ }^{4}$ University of Transport Technology, 54 TrieuKhucstreet, ThanhXuan, Hanoi, Vietnam
}

\begin{abstract}
Steel fiber reinforcement in high performance concrete (HPC) has good resistance over the cracks propagation. High performance concrete can satisfy the distinctive necessities such as consistence and uniform characteristics which could be performed normally with the utilization of conventional materials and minimum grinding, placement and healing. Reinforcement of fiber to high performance concrete imcreases its capability in arresting the cracks, fiber combination can improve extensibility and tensile strengths, both at first and critical cracking, predominantly under flexural processing, and even after major cracking, the fiber keeps the matrix together. Finally, it is to send the pronounced post to the fiber composite-unheard of ductility breaks. Switching from the brittle materials to ductable materials can considerably enhance the energy absorption property of fibre and it's capability in resisting the constant utilization and loading related impacts.
\end{abstract}

KEYWORDS: High performance concrete,Sustainable materials,Steel fiber,Mechanical properties\&Durability

Received: Jun 09, 2020; Accepted: Jun 29, 2020; Published: Aug 14, 2020; Paper Id.: IJMPERDJUN2020772

\section{INTRODUCTION}

Steel Fiber Reinforcement in High Performance Concrete (SFRHPC) is a composite material containing asphalt, soil, fine and coarse aggregates and a thin, distinct fibre- dispersion layer. The HPC is the concrete with the same basic ingredients but has a completely different microstructure from that of ordinary concrete. The reinforced concrete structures undergo cyclic loads under shocks from earthquakes. The High Performance concrete is used for most construction applications to refer to concrete of appropriate performance. Since one can still strive to achieve the following characteristics:

- Low porosity.

- $\quad$ Low diffusion and permeability.

- $\quad$ High chemical resistance.

- In the case of Mass concrete, high hydration pressure.

- $\quad$ High early strength and continued development strength.

- $\quad$ Strong durability in extreme environments and long service life.

- $\quad$ Lower water -cement ratio.

- $\quad$ Low bleeding and plastic shrinkage. 
- Inhibition of bacterial growth and mould growth.

\section{OBJECTIVES}

- To achieve sustainable high- performance concrete construction using alternative concrete materials.

- Investigate their mechanical properties.

- To increase the resistance to breakage, deflection and other requirements of serviceability of conventionally built structural components, using the intrinsic material properties of fiber concrete.

- $\quad$ Check for the durability of SFRHPC Beams.

\section{Research Significance}

In the modern construction environment, designing durable high-performance concrete is a must. That will reduce the construction time dramatically. HPC offers substantially improved environmental impact tolerance, thereby also enhancing the systemic efficiency. Ductility is important in seismic powered reinforced concrete frames. In this way, reinforced high performance concrete made from steel fiber can be seen as a replacement for plain concrete. The use of high-performance concrete beam supported by steel fibre is intended to partially or completely remove the links, while preventing obstruction in reinforcement.

\section{Literatures relevant to the study were collected under the following heads}

- $\quad$ Mix proportion optimization of HPC

- $\quad$ Replacement of binder materials

- $\quad$ Replacement of fine aggregate

- $\quad$ Replacement of coarse aggregate

- Uses of super plasticizer in HPC

- $\quad$ Admixtures

Key findings obtained from the reviews are as follows:

- Adel Kaikeaet.al, (2014): The presence of steel fibers has a significant influence on HPC's compressive strength. For a volume fraction of 2 per cent of blast furnace slag, the compressive strength improves by about 30 percent [1]

- PiotrSmarzewskia, et al (2019): The presence of silica fume shows the increase in compressive strength, mean frequency of tensile cracking and elasticity modulus to significant percentages [2].

- Aissa. Talah et.al (2015): In this paper the increase in durability is observed without reducing the concrete's compressive strength [3].

- TalahAissa (2018): It can be concluded that the fly ash is suitable for the composition of high-performance concrete and its properties are considerably higher than the reference concrete (RC). The findings demonstrate the beneficial effect of PW under hydrochloric media on concrete properties [4]. 
- Gérard-Philippe Zéhilet.al, (2019): Shrinkage in concrete drying is adversely affected by use of XLPE. Reducing the w/c ratio effectively mitigates the rising drying shrinkage induced by the addition of XLPE [5]

- Anjaneya Dixit et. al (2019): This study shows that the degree of hydration calculated was increased from 42 percent to 50 percent in biochar blends; the most impressive was 59 percent. All biochar mixes showed higher hydration pressure [6].

- Rami A. Hawileh, AbdolrezaKhaliliet.al (2017): Massive use of GGBS rather than cement will greatly affect $\mathrm{CO} 2$ mitigation resulting from cement processing. Therefore, the environmental issue of global warming can be largely solved [7].

- Dima M. Kennan, Sherif H. Aboubaker, et.al (2017): This paper shows that the high-performance concrete can be developed by replacing Portland cement with CWP between 20 - 40 per cent. The resultant concrete will have lesser early-age compressive strength and more late-age compressive strength compared to normal concrete mixtures without CWP [8].

- D.Pedro, J. de Brito et al, (2017): With respect to RC, the compressive intensity reductions of RAC were always below 15 per cent. Conclusions regarding resilience performance, recycled aggregates, and silica fume addition resulted in higher water absorption values [9].

- Oorkalan, S. Chithra, (2018): This research investigates the potential use of an agro-waste under normal healing and self-healing conditions as a partial replacement for natural concrete sand. The workability of concrete made from 5 per cent coconut coir pith shows matching workability with standard concrete, beyond which workability is significantly improved [10].

- M. Vinay Kumar, et.al, (2017): The use of recycled materials collected from concrete waste can be used at replacement levels of 20 per cent to create HPC blends for recycling requirements in terms of consistency. HPC test results of $20 \%$ CRCA, 20\% FRCA and 20\% all indicate strengths of approximately $0.98,1.18$ and 1 [11].

Some studies of Nano concrete with steel fibers [12-14], concrete with steel fiber in shell structure, in beam structure [15-19], and some another studies [20-26], etc.

\section{Summary of review of literature:}

- $\quad$ Silica particles as partial cement substitute have improved all the mechanical properties of concrete.

- The studies also show that the corrugated steel fabrics are more effective in reducing the crack width than free shrinkage values.

- The introduction of ceramic waste powder has substantially improved the toughness characteristics of HPC concrete production.

- The literature clearly shows that the characteristics of core HP concrete reinforced with steel reinforcement are determined by the action of RC beams.

- Many researchers have found the use of steel fibers as an additive in HPC to significantly improve concrete tensile strength and ductility. 


\section{MATERIALS AND METHODS}

\subsection{Materials}

Specimens were prepared using the following raw materials:

- $\quad$ Ordinary Portland cement (OPC)-Ordinary Portland was used during the entire investigation. The cement used was tested for various properties. Cement's properties are, as shown in the tablebelow

Table 1:Properties of Cement

\begin{tabular}{|c|l|c|c|}
\hline No & \multicolumn{1}{|c|}{ Properties } & Experimental Results Standard Values \\
\hline 1 & Fineness of Cement & $3.9 \%$ & $<10 \%$ \\
\hline 2 & Specific Gravity & 3.15 & - \\
\hline 3 & $\begin{array}{l}\text { Initial setting } \\
\text { time }\end{array}$ & $45 \mathrm{~min}$ & $>30$ Minutes \\
\hline
\end{tabular}

\section{Coarse Aggregate}

Physical properties of aggregates have been tested according to standard, such as fineness modulus, basic gravity, bulk density. The properties of the aggregates of course are as shown in the following table.

Table 2:Properties of Course Aggregate

\begin{tabular}{|c|c|c|c|}
\hline No & Property & $\begin{array}{c}\text { Experimental } \\
\text { Results }\end{array}$ & $\begin{array}{c}\text { Standard } \\
\text { Values }\end{array}$ \\
\hline 1 & Specific Gravity & 2.65 & $2.60-2.90$ \\
\hline
\end{tabular}

\section{FineAggregate}

The physical properties of natural river sand moving through a sieve of $4.75 \mathrm{~mm}$ has been used. Tests such as sieve examination, basic gravity, bulk density etc is calculated. Fine aggregate properties are as shown in table 3 :

Table 3: Properties of Fine Aggregate

\begin{tabular}{|c|c|c|c|}
\hline No & Property & Experimental Results & \\
\hline 1 & SpecificGravity & 2.62 & $2.60-2.90$ \\
\hline 2 & Sieve Analysis & Zone II grading & \\
\hline
\end{tabular}

- Water -Portable water, free of all organic impurities, is used throughout the concrete preparation and cureprocess.

- SteelReinforcement- HYSD bars of $12 \mathrm{~mm}, 10 \mathrm{~mm}$ as used as main bars with $8 \mathrm{~mm}$ bars as shear reinforcement.

- Fibres:Hooked end, Crimped fibres were used with following aspect ratios and diameters. Fibre properties are as shown in table 4:

Table 4: Properties of Fibres

\begin{tabular}{|c|l|c|c|c|}
\hline No & \multicolumn{1}{|c|}{ Fiber } & $\begin{array}{c}\text { Aspect } \\
\text { ratio }(\mathbf{l} / \mathbf{d})\end{array}$ & $\begin{array}{c}\text { Length } \\
(\mathbf{m m})\end{array}$ & $\begin{array}{c}\text { Diameter } \\
(\mathbf{m m})\end{array}$ \\
\hline 1 & Hook End -1 & 80 & 60 & 0.75 \\
\hline 2 & Hook End -2 & 65 & 35 & 0.55 \\
\hline 3 & Hook End -3 & 45 & 0 & 1.11 \\
\hline 4 & Crimped & 50 & 50 & 1 \\
\hline
\end{tabular}




\subsection{Mix Design and Testing}

Taking into account the efficiency of the beam testing machine. Concrete mix is as shown in the table 5:

Table 5: Mix Design

\begin{tabular}{|c|c|c|c|}
\hline Water & Cement & Fine aggregate & $\begin{array}{c}\text { Coarse } \\
\text { aggregate }\end{array}$ \\
\hline 214.24 & 465.7 & 506.52 & 1123.6 \\
\hline 0.46 & 1 & 1.08 & 2.41 \\
\hline
\end{tabular}

\subsubsection{Design of RC Beam}

The limiting load added from the machinery to the beam is estimated to be $250 \mathrm{kN}$. The dimensions and reinforcement information are as shown in the figure 1

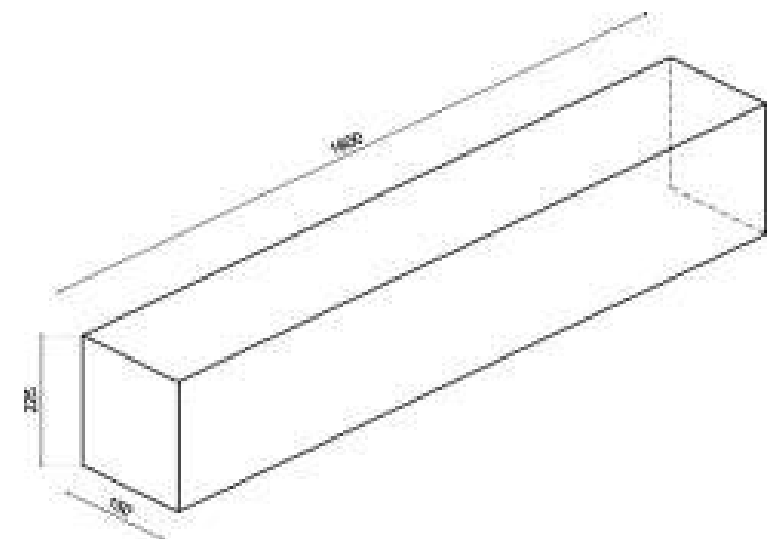

a) Cross sectional details of Beam.
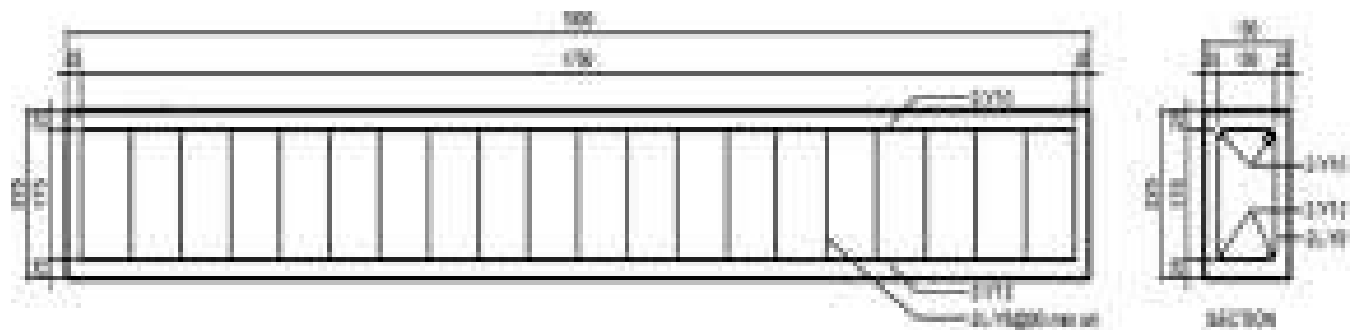

b) Reinforcement Detail 1

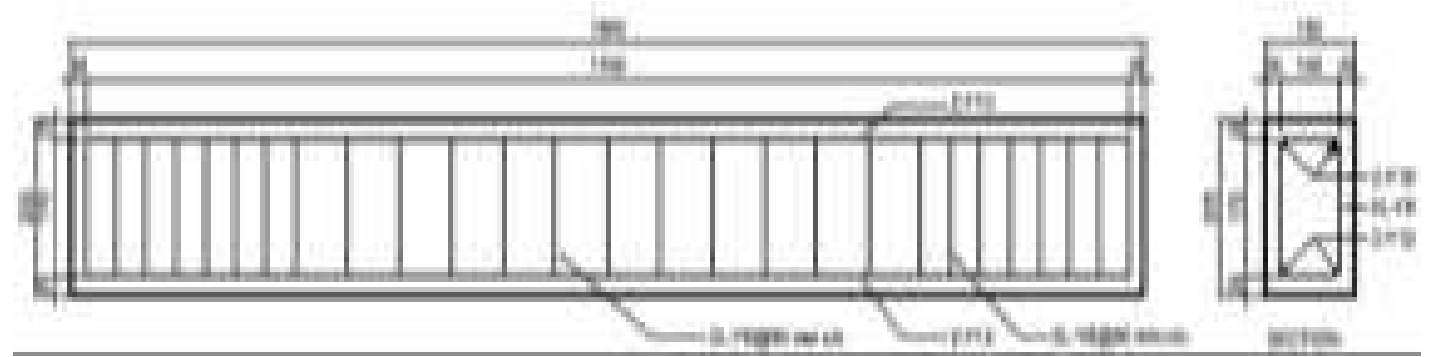

c) Reinforcement Detail 2

Figure 1: Design of RC Beam

\subsubsection{Test Specimen}

Details of test specimen are as shown in table 6 
Table 6: Test Specimen details

\begin{tabular}{|c|c|c|c|}
\hline No & Specifications & $\begin{array}{c}\text { Volume Fraction Vf } \\
(\%)\end{array}$ & $\begin{array}{c}\text { Aspect Ratio } \\
(\mathbf{L} / D)\end{array}$ \\
\hline 1 & M1 & ---- & ---- \\
\hline 2 & M2 & $1 \%$ & 50 \\
\hline 3 & M3 & $1 \%$ & 80 \\
\hline 4 & M4 & $1 \%$ & 65 \\
\hline 5 & M5 & $1 \%$ & 45 \\
\hline 6 & M6 & $(0.5+0.5) \%$ & $50+80$ \\
\hline 7 & M7 & $(0.5+0.5) \%$ & $50+65$ \\
\hline 8 & M8 & $(0.5+0.5) \%$ & $80+45$ \\
\hline
\end{tabular}

\subsubsection{Scheme of Test}

Analysis of all eight beam experiments under complete cyclic loading was conducted. The loads are distributed incrementally at the mid-span of the experiment, as positive and negative intervals. To achieve cyclic loading effect, hydraulic jack and load cells (10 tonnes or 25 tonnes) are mounted above and below the beam. The load was added incrementally from the bottom at the beginning of the positive process and then it is slowly reduced to zero. In this case, the deflection is determined in ascending direction. Afterwards, load was applied from top to mid range in the reverse process and deflection downwards is assessed. That beam is checked for corresponding increase in load and eventually the beam behaviour is observed. Full deflection is achieved at the maximum load. For both loading and unloading, load and deflection values have been obtained.

\section{RESULTS AND DISCUSSIONS}

- $\quad$ Modulus of elasticity

- $\quad$ Flexural strength

- $\quad$ Load-deflectioncurve

Results are obtained for all the cylindrical specimens, with different volume fractions of fiber. The corresponding load deflection curve and the ultimate load curve were plotted. They are as shown in the figures2.

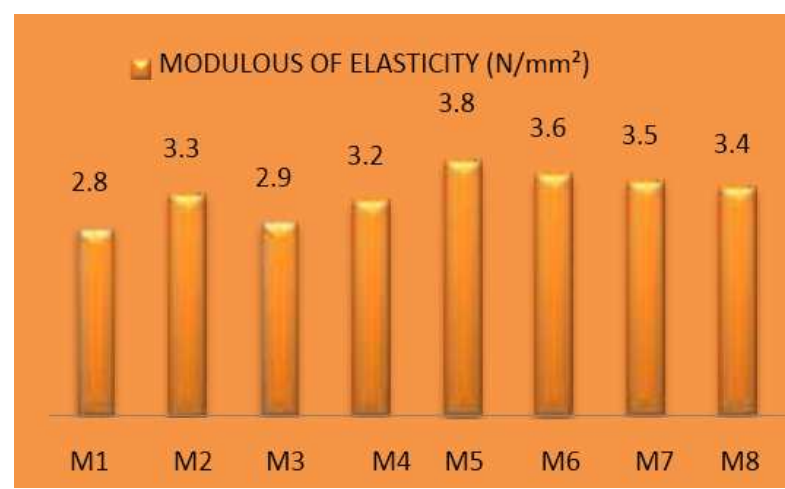

a. Bar chart showing Modulus of Elasticity 


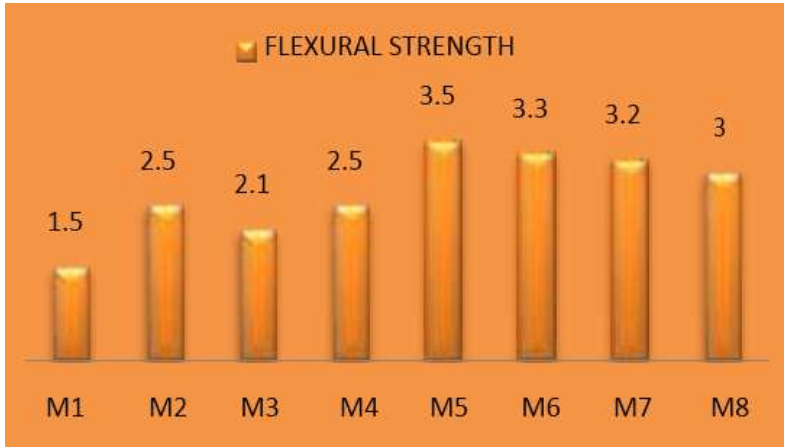

\section{b. Bar chart showing Flexural Strength}

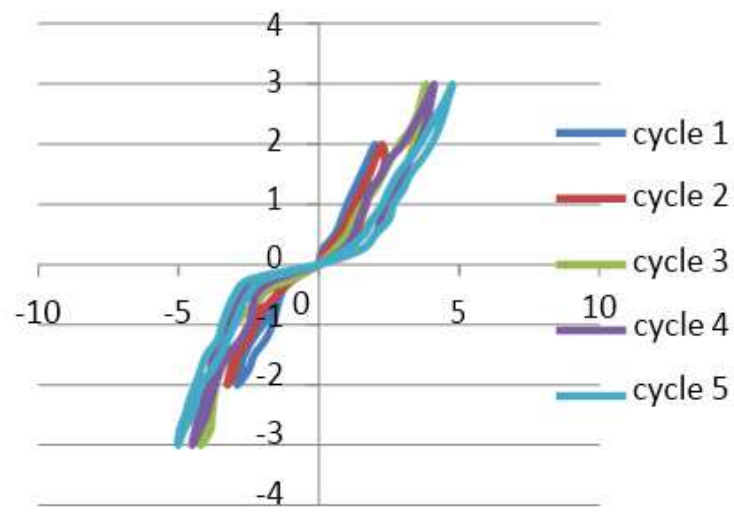

c. Load deflection curve

Ultimate Load

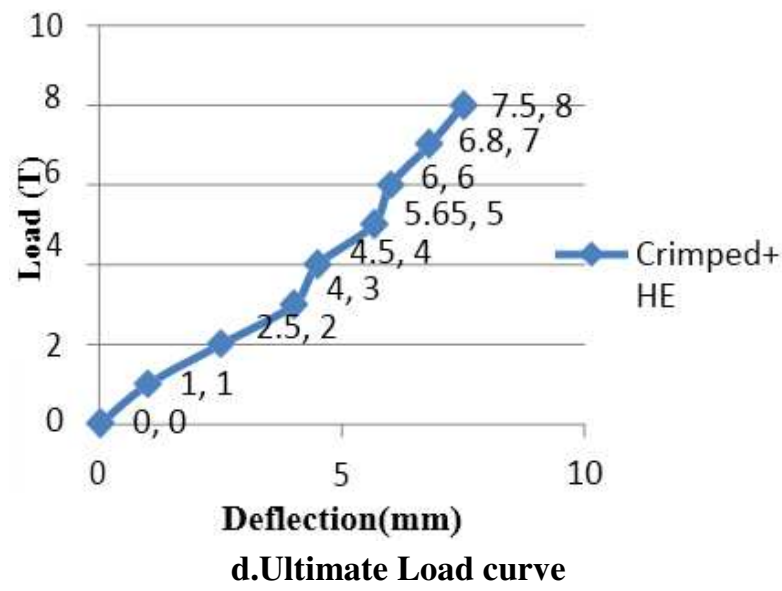

Figure 2: Modulus of elasticity, Flexural strength, Load-deflectioncurve

\section{CONCLUSIONS}

Based on the results of the study lead to the following conclusions:

The experimental values of strain and deflection of reinforced concrete beams made of steel fiber are compared with the estimated equal strain values and deflection of reinforced concrete beams without fibre. The analysis shows that the intensity depends on the quality of the fibers and decreases with decreased stirrup spacing (increase in percentage of network strengthening). The ultimate strength of the SFRHPC beams is obtained, based on the experimental results. 


\section{REFERENCES}

1. T. Aissa, B. Rachid, and F. Kharchi. Effect of Pharmaceutical Wastes Usage as Partial Replacement of Cement on the Durability of High-Performance Concrete. ProcediaStruct. Integr., 13, 2018. Pp. 218-221.

2. A. Dixit, S. Gupta, S. D. Pang, and H. W. Kua. Waste Valorisation using biochar for cement replacement and internal curing in ultra-high performance concrete. J. Clean. Prod., 238. 2019. Pp. 117876.

3. D. M. Kannan, S. H. Aboubakr, A. S. EL-Dieb, and M. M. RedaTaha. High performance concrete incorporating ceramic waste powder as large partial replacement of Portland cement. Constr. Build. Mater., 144. 2017.Pp. 35-41.

4. Rao, N. Venkat, B. Suresh, and K. Arun Kumar. "Evaluation of Mechanical Properties of Steel Fibre Reinforced Concrete with OPC43 and 53 Grades." International Journal of Mechanical and Production Engineering Research and Development 8.2: 221-228.

5. M. S. Meddah, M. Suzuki, and R. Sato. Influence of a combination of expansive and shrinkage- reducing admixture on autogenous deformation and self-stress of silica fume high-performance concrete. Constr. Build. Mater., 25(1). 2011.Pp. 239250.

6. A. Mehta and D. K. Ashish. Silica fume and waste glass in cement concrete production: A review. J. Build. Eng., No. July, 2019. Pp. 100888 .

7. Dogra, Aditya, AkshinaSoni, and YogeeshaPai. "An experimental study on the mechanical properties Of basalt and banana fiber reinforced Hybrid polymer composites." International Journal of Mechanical and Production Engineering Research and Development 9.1 (2019): 263-270.

8. A. Oorkalan and S. Chithra.,Effect of coconut coir pith as partial substitute for river sand in eco-friendly concrete. Mater. Today Proc., 2019.

9. D. Pedro, J. de Brito, and L. Evangelista. Evaluation of high-performance concrete with recycled aggregates: Use of densified silica fume as cement replacement. Constr. Build. Mater.,147. 2017.Pp. 803-814.

10. D. Pedro, J. de Brito, and L. Evangelista. Durability performance of high-performance concrete made with recycled aggregates, fly ash and densified silica fume.Cem. Concr. Compos., 93. 2018.Pp. 63-74.

11. P. Smarzewski. Influence of silica fume on mechanical and fracture properties of high performance concrete.ProcediaStruct. Integr., 17. 2019.Pp. 5-12, 2019.

12. A. Talah, F. Kharchi, and R. Chaid. Influence of Marble Powder on High Performance Concrete Behavior. Procedia Eng., 114. 2015.Pp. 685-690.

13. B. M. Vinay Kumar, H. Ananthan, and K. V. A. Balaji. Experimental studies on utilization of recycled coarse and fine aggregates in high performance concrete mixes. Alexandria Eng. J., 57(3). 2018.Pp. 1749-1759.

14. Ngo, V.T., Lam, T.Q.K., Do, T.M.D., Nguyen, T.C. Nano concrete aggregation with steel fibers: A problem to enhance the tensile strength of concrete. E3S Web of Conferences, 135 03001, 2019. DOI: 10.1051/e3sconf/201913503001

15. Ngo, V.T., Lam, T.Q.K., Do, T.M.D., Nguyen, T.C. Increased plasticity of nano concrete with steel fibers. Magazine of Civil Engineering, 1(93), 2020.DOI: 10.18720/MCE.93.3

16. Ngo, V.T., Bui, T.T., Lam, T.Q.K., Nguyen, T.T.N., Nguyen, V.H. Experimental Evaluation of Nano Silica Effects to High Performance Concrete Strength in Early Age. IOP Conf. Series: Materials Science and Engineering, 869 032011, 2020. DOI: 10.1088/1757-899X/869/3/032011 
17. Khai, L.T.Q., Dung, D.T.M. Stress-strain in multi-layer reinforced concrete doubly curved shell roof. International Journal of Innovative Technology and Exploring Engineering, 8(4S2), 2019.Pp. 419-424.

18. Lam, T.Q.K., Do, T.M.D. Effect of each shell thickness on deformation stress and the ability for causing the cracks in the multilayer doubly curved shell roof. International Journal of Innovative Technology and Exploring Engineering, 8(6C2), 2019.Pp. 215-220.

19. Lam, T.Q.K., Do, T.M.D. Sliding between layers in 2-layer reinforced concrete beams and shell. International Journal of Engineering and Advanced Technology, 8(5), 2019. Pp. 1867-1871.

20. Lam, T.Q.K., Do, T.M.D., Ngo, V.T., Nguyen, T.C., Huynh, T.P. Numerical simulation and experiment on steel fiber concrete beams. J. Phys.: Conf. Ser., 1425 012007, 2019. DOI: 10.1088/1742-6596/1425/1/012007

21. Do, T.M.D., Lam, T.Q.K. Design parameters of steel fiber concrete beams. Magazine of Civil Engineering, 2(102), 2021.

22. Tran, H.Q., Lam, T.Q.K., Do, T.M.D. Model of prefabricated concrete frame in the condition of southern Vietnam. E3S Web of Conferences. 135 03043, 2019. DOI: 10.1051/e3sconf/ 201913503043

23. Natrayan, L., Maharshi Singh, and M. Senthil Kumar. "An experimental investigation on mechanical behaviour of SiCp reinforced Al 6061 MMC using squeeze casting process." Inter J Mech Prod Engi Res Develop 7.6 (2017): 663-668.

24. Do, T.M.D., Lam, T.Q.K., Ngo, V.T. Analysis of axial stiffness reduction factors in thermal analysis of multistorey buildings. International Journal of Advanced Science and Technology. 29(8s), 2020. Pp. 1378-1390.

25. Do, T.M.D., Lam, T.Q.K.,. Quality of Construction Works at the Design Phase. Lecture Notes in Civil Engineering, $70,2020$. Pp 15-24. DOI: 10.1007/978-3-030-42351-3_2

26. Lam, T.Q.K., Do, T.M.D., Truong, C.B., Analysis of Structural Failures and Remedial Measures. International Journal of Advanced Science and Technology, 29(8s), 2020.Pp. 2780-2786.

27. Do, T.M.D., Nguyen, T.C., Lam, T.Q.K. Investigating the effectiveness of insulation for walls of buildings in Vietnamese climatic condition. IOP Conf. Series: Materials Science and Engineering, 869 032008, 2020. DOI: 10.1088/1757$899 X / 869 / 3 / 032008$

28. Suman, P., A. Lakshumu Naidu, and P. R. Rao. "Processing and mechanical behaviour of hair fiber reinforced polymer metal matrix composites." International Journal of Mechanical and Production Engineering Research and Development 469 (2016): 478.

29. Do, T.M.D., Lam, T.Q.K. Solutions to improve the quality of mass concrete construction in climate conditions of Southern Vietnam. International Journal of Innovative Technology and Exploring Engineering, 8(6C2), 2019. Pp. 188-192.

30. Do, T.M.D., Lam, T.Q.K. Analysis of Risk Problems in Construction by R software. International Journal of Engineering and Advanced Technology, 8(5), 2019. Pp. 1872-1875. 

